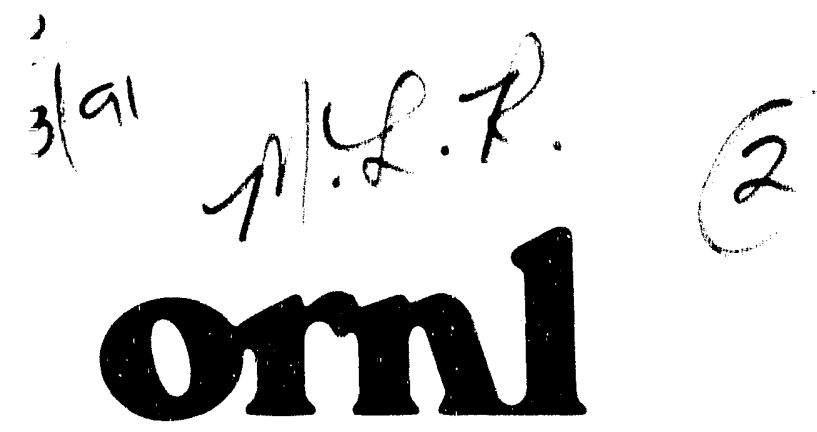

ORNL/TM-11591

OAK RIDGE

NATIONAL

LABORATORY

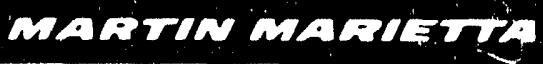

\section{Automated Operator Procedure Prompting for Startup of Experimental Breeder Reactor-II}

A. W. Renshaw

S. J. Ball

C. E. Ford 
This report has been reproduced directly from the best available copy.

Available to DOE and DOE contractors from the Office of Scientific and Technical Information, P.O. Box 62, Oak Ridge, TN 37831; prices available from (615) 576-8401, FTS 626-8401.

Available to the public from the National Technical Information Service, U.S. Department of Commerce, 5285 Port Royal Rd., Springfield, VA 22161.

NTIS price codes-Printed Copy: $A 03$ Microfiche $A 01$

This report was prepared as an account of work sponsored by an agency of the United States Government. Neither the United States Government nor any agency thereof, nor any of their employees, makes any warranty, express or implied, or assumes any legal liability or responsibility for the accuracy, com. pleteness, or usefulness of any information, apparatus, product, or process disclosed, or represents that its use would not infringe privately owned rights. Reference herein to any specific commercial product, process, or service by trade name, trademark, manufacturer, sr otherwise, does not necessarily constitute or imply its endorsement, recommendation, or favoring by the United States Government or any agency thereof. The views and opinions of authors expressed herein do not necessarily state or reflect those of the United States Government or any agency thereof. 
ORNL/TM-11591

Distribution Category UC-5(1).5

Mathematics and Computer Sciences

Instrumentation and Controls Division

\section{AUTOMATED OPERATOR PROCEDURE PROMPTING FOR STARTUP OF EXPERIMENTAL BREEDER REACTOR-II}
A. W. Renshaw
S. J. Ball
C. E. Ford

Date Published: November 1990

Prepared for

Division of Advanced Technology Development

U.S. Department of Energy

Prepared by the

OAK RIDGE NATIONAL LABORATORY

Oak Ridge, Tennessee 378.31

managed by

MARTIN MARIETTA ENERGY SYSTEMS, INC.

for the

U.S. DEPARTMENT OF ENERGY

under Contract No. DE-AC05-84OR21400) 


\section{CONTENTS}

Page

LIST OF FIGURES $\ldots \ldots \ldots \ldots \ldots \ldots \ldots \ldots \ldots \ldots \ldots \ldots \ldots \ldots$

LIST OF SYMBOLS $\ldots \ldots \ldots \ldots \ldots \ldots \ldots \ldots \ldots \ldots \ldots \ldots \ldots \ldots \ldots$

ABSTRACT $\ldots \ldots \ldots \ldots \ldots \ldots \ldots \ldots \ldots \ldots \ldots \ldots \ldots \ldots \ldots \ldots \ldots \ldots \ldots \ldots$

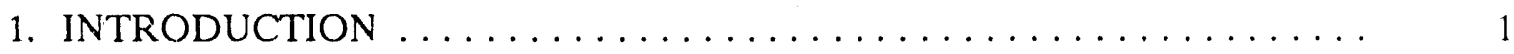

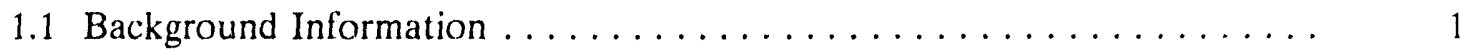

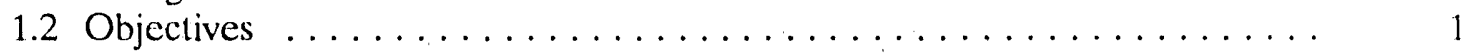

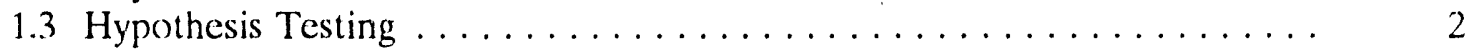

2. GENERAL DESCRIPTION OF REACTOR STARTUP PROCEDURES .. 3

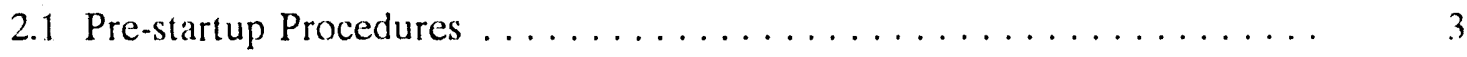

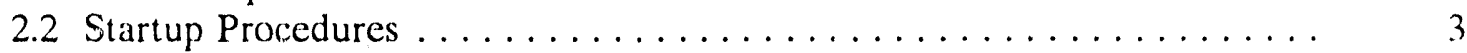

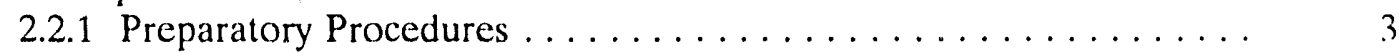

2.2.2 Direct Procedures . . . . . . . . . . . . . . . . . . . 3

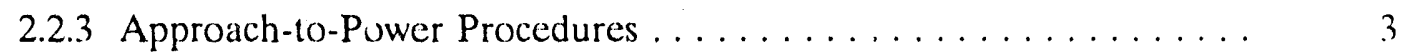

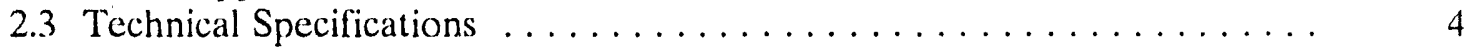

3. TWO METHODS FOR PROCEDURE PROMPTING $\ldots \ldots \ldots \ldots \ldots \ldots$

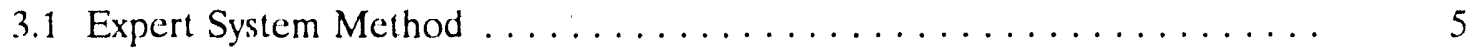

3.1.1 Computer Hardware and Software $\ldots \ldots \ldots \ldots \ldots \ldots \ldots \ldots \ldots$

3.1.2 Description of Expert System Procedure Prompting Method . . . . . . 6

3.1.3 Description of KES Expert System Features Used for

Procedure Prompting $\ldots \ldots \ldots \ldots \ldots \ldots \ldots \ldots \ldots \ldots \ldots$ 10

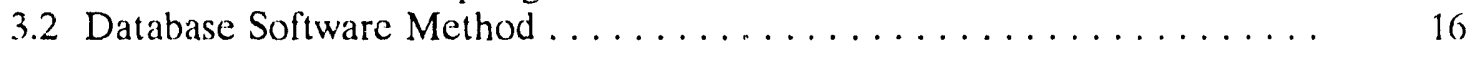

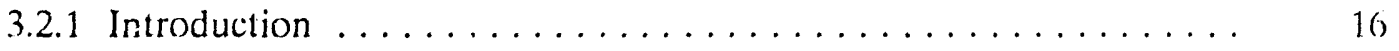

$\begin{array}{ll}\text { 3.2.2 Description of Database Prototype Procedure Prompting Method . } & 17\end{array}$

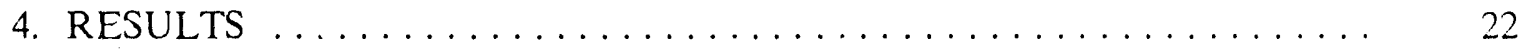

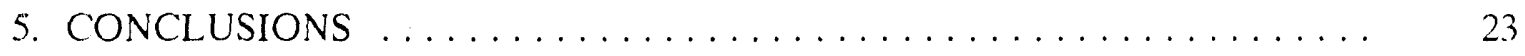

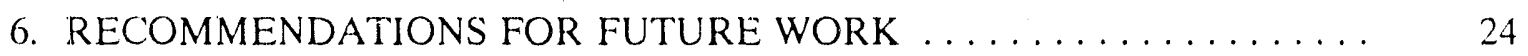

6.1 Improvements to Procedure Prompting ................... 24

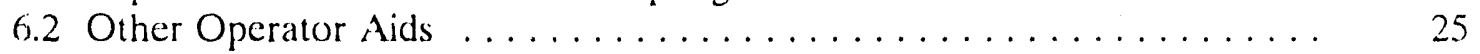

6.2.1 Equipment Maintenance Record Database . . . . . . . . . . . . 25

6.2.2 Technical Specifications Monitor . . . . . . . . . . . . . . . 25

6.2.3 Emergency Operating Procedures Advisor . . . . . . . . . . . . . . 2.5

6.2 .4 Portable Computer . . . . . . . . . . . . . . . . . . . . 25

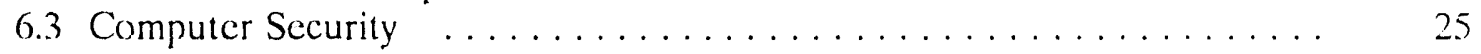

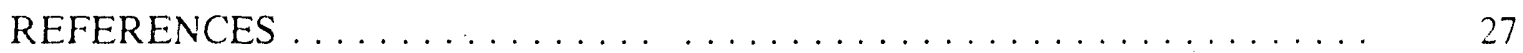




\section{LIST OF FIGURES}

Figure

Pilgc

1. Sun Workstation screen display of preliminary information on starlup

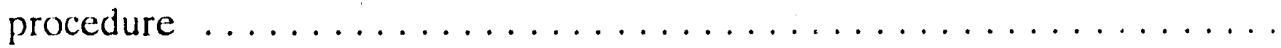

2. Sun Workstation screen display of operator prompt for direct procedure step DP1 . . . . . . . . . . . . . . . . . . .

3. Sun Workstation screen display of operator prompt for direct procedure step DP15, a control point requiring Shift Supervisor's signature . . . . . . .

4. Sun Workstation screen display of operator prompt for direct procedure step DP15, procedure status $\ldots \ldots \ldots \ldots \ldots \ldots \ldots \ldots \ldots$

5. Sun Workstation screen display of operator prompt for input of

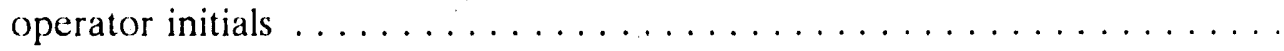

6. Sun Workstation screen display of operator prompt for direct procedure step DP7, requiring data input by operator $\ldots \ldots \ldots \ldots \ldots \ldots \ldots$

7. Sun Workstation screen display of technical specifications

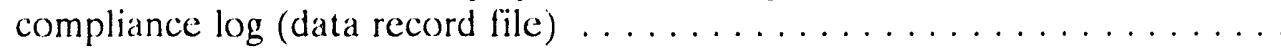

8. Database prototype, main menu ...................... is

9. Database prototype, preparatory procedures run selection screen . . . . . . is

10. Database prototype, example summary status report for preparatory

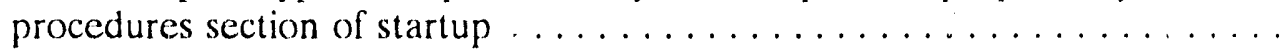

11. Database prototype, preparatory procedures action menu $\ldots \ldots \ldots \ldots \ldots$

12. Database prototype, "pick" style checklist screen for preparatory procedures

13. Database prototype, direct procedures run selection with summary status report

14. Database prototype, "pick" style checklist for first part

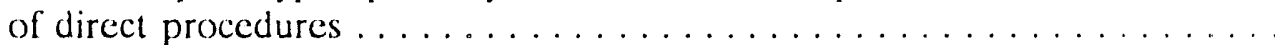




\section{LIST OF SYMBOIS}

$\mathrm{ACP}$

ALMR

ANL-W

AP

APP

DAS

DOS

DP

EBR-II

EOP

KES

ORNL

$P C$

PP

UNIX
Advanced Controls Program

Advanced Liquid Metal Reactor

Argonne National Laboratory - West

Approach-to-power procedure

Automated procedure prompting

Data acquisition system

Operating system (on IBM PC)

Direct procedures

Experimental Breeder Reactor II

Emergency Operating Procedures

Knowledge Engineering System

Oak Ridge National Laboratory

Personal computer

Preparatory procedures

Operating system (on Sun Workstation) 


\begin{abstract}
This report describes the development of an operator procedure prompting aid for startup of a nuclear reactor. This operator aid is a preliminary design for a similar aid thal eventually will be used with the Advanced Liquid Metal Reactor (ALMR) presently in the design stage. Two approaches were used to develop this operator procedure prompting aid. One method uses an expert system software shell, and the other method uses database software. The preliminary requirements strongly pointed toward leatures traditionally associated with both database and expert systems software. Database: software usually provides data manipulation flexibility and user interface tools, and expert systems tools offer sophisticated data representation and reasoning capabilities. Both methods, including software and associated hardware, are described in this report.

Proposals for future enhancements to improve the expert system approach to procedure prompting and for developing other operator aids are also offered.
\end{abstract}




\section{INTRODUCTION}

\subsection{BACKGROUND INFORMATION}

Under the auspices of the Advanced Controls Program (ACP) at the Oak Ridge National Laboratory (ORNL), a computer-based operator aid is being developed to assist operators in starting up a nuclear reactor. This operator aid is a preliminary design for a similar aid that eventually will be used with GE Nuclear Energy's innovative conceptual design for an advanced liquid metal reactor (ALMR) to be built in the 21 st century. This operator aid, called automated procedure prompting (APP), will guide the operator through the startup procedure instructions, request that certain actions be taken by the operator, and record information input by the operator.

At the present time U.S. research and power reactors generally rely solely on humans to carry out these tasks without computer aids. Preliminary demonstrations of this operator aid to nuclear plant personnel indicate that this can be a useful tool to assist reactor operators.

\subsection{OBJECTIVES}

The objectives to be achieved via automated procedure prompting for startup involve human as well as safety factors. One human factors objective is to reduce the voluminous number of time-consuming tasks performed by the operators and thus reduce their workload and stress. Another human factors objective is to present backup information (such as technical specifications references and surveillanee requirements) to the operator in a format that is easily understood. One safety factor objective is $t$; improve the safety of the startup operation by ensuring operator accuracy in the performance of startup tasks.

Startup is one of the most procedure-intensive phases of nuclear reactor operation. Procedure prompting helps ensure that startup actions and documentation are complete, that tasks are performed in the proper sequence, and that execution of procedural sleps is chec red via plant response (data acquisition system feedback). An additional benefit of automated procedure prompting is a more complete record of relevant information (date and time for each event recorded automatically) that can be important for post-run revicw and analysis. A report of startup actions is initiated when startup begins and is generated automatically during the process.

Another important objective was to design the APP sysaem to alecommodate changes in the procedures. Preliminary results of demonstrations to various Experimental Breceder Reactor II (EBR-II) operations and engineering personnel have indicated that automated procedure prompting can aid the operator in performing lasks with increased accuracy and efficiency and therefore improve salety in the startup and operation of the reactor.

A demonstration of this operator prompting procedure will be reviewed and critically evaluated by operations personnel at the EBR-II site in Idaho. Additional critical analyses are expected to be made by human factors personnel on the ACP stafit at ORNL. 


\subsection{HYPO'THESIS TESTING}

The operator procedure prompting software being developed under ACP auspices at ORNL will be tested on the EBR-II using existing instrumentation. EBR-II is located $\sim 35$ miles west of Idaho Falls, Idaho and is operated by Argonne National LaboratoryWest (ANL-W).

EBR-II is a pool-typ, uranium-plutonium-fueled, liquid-metal reactor with a maximum power level of $62.5 \mathrm{MW}$ thermal capacity. The steam plant generates $19 \mathrm{MW}$ of electrical power through a conventional turbine generator for on-site use and for the power grid of the Idaho National Engineering Laboratory.

EBR-II was initially started up in 1964 and has been modified continuously to improve safety and to provide new experimental capabilities. These include a computerbased data acquisition system (DAS) for collecting and recording data from plant instruments. The present system can accommodate 1000 input signals, and 9.31 channels are in use for sensor values or calculated values. The DAS samples data from each sensor at the rate of 10 readings/s, averages these values, and stores the data every minute on magnetic tape along with the date and time for historical purposes. Reactor Operations personnel use a screen menu to retrieve a graphical display of collected data vs time period (several period options are available ranging from a few hours to 90 days).

A critical evaluation of the impact of the APP on nuclear reactor operator performance will be made by ANL-W personnel at their site. Testing of APP during a dry run of startup at a reactor site is expected to result in more specific comments from experienced reactor operators that can be used to modify the program and deliver a better product. The EBR-II will afford exposure to a large number of reactor operations personnel. Other human factors aspects of this operator aid such as cognitive modeling will be evaluated by human factors personnel on the ACP staff at ORNL. 


\section{GENERAL DESCRIPTION OF REACTOR STARTUP PROCEDURES}

Documents describing EBR-II startup procedures have been provided to ORNL for use in preparing the operator aid for procedure prompting. These documents include operating instructions, ${ }^{1}$ technical specifications compliance log checksheets, ${ }^{2,3}$ and technical specifications. ${ }^{4}$ Basically, these are detailed written instructions called "procedures" and technical specification compliance log "checklists" used by the reactor operators and other plant operations personnel during the startup operation. The checklist serves as hardcopy documeniation for each startup event.

\subsection{PRE-STARTUP PROCEDURES}

Prior to startup of the reactor, certain subsystems must be checked by the operator to ensure that they are operable and that their standby status conditions are at the “ $\mathrm{p}$ propriate level for startup of the reactor. These subsystems are electrical system, radiation monitoring system, auxiliary system, reactor control system, fission product monitors, secondary sodium and cover gas controi system, and primary system. Pre-startup procedures are not being automated at this time because operations management personnel want the operators to continue to collect the data in the field with checksheets.

\subsection{STARTUP PROCEDURES}

The three major calegories of startup procedures (preparatory, direct, and approach-to-power procedures) currently being automated for procedure prompting are described briefly below.

\subsubsection{Preparatory Procedures ${ }^{1,2}$}

These procedures direct the operator to ensure that all the reactor plant system components such as power supplies, equipment, instrumentation, annunciators, and the DAS are operable and set at the appropriate status conditions for beginning the reactoi startup operation. There are 12 steps in the preparatory procedures.

\subsubsection{Direct Procedures ${ }^{1,2}$}

These procedures instruct the operator to activate certain subsystems, equipment, instrumentation, and the DAS, and to verify their status. These procedures permit the operator to bring the plant up to a minimum steady-state power level in the range of $50 \mathrm{to}$ $400 \mathrm{~kW}$ thermal capacity. There are 26 major steps in the direct procedures.

\subsubsection{Approach-to-Power Procedures ${ }^{1,3}$}

These procedures permit the operator to bring the plant to full-power operation in $10-\mathrm{MW}(\mathrm{t})$ steps. The turbine generator is placed on-line during approach to power at $30 \mathrm{MW}(\mathrm{t})$. There are seven major steps in the approach-to-power procedures. 


\subsection{TECHNICAL SPEC.IFICATIONS ${ }^{4}$}

EBR-II technical specifications define safety limits, limiting safety systems scttings, limiting conditions for facility operation, subassembly irradiations, surveillance reguirements, design features, and administrative controls. Basic safety limits are designed to ensure protection of personnel and property by protecting against inadvertent radioactive releases to the environment. Limiting safety system settings define those settings of the various control and safety system devices to values that avoid violations of the safety limits. Limiting conditions for facility operation are limiting conditions for operation of equipment (systems and components) and technical characteristics of the plant that ensure safe facility operation. Surveillance requirements are those tests and procedures that ensure the operability of the essential systems and equipment. Design features apply to those aspects of basic plant design that are important to salety and have not been included in previous limits. Administrative controls describe organization and managerial procedures deemed necessary to provide assurance and evidence that safe facility operation will be achieved and maintained. 


\section{TWO METHODS FOR PROCEDURE PROMPTING}

The preliminary requirements strongly pointed toward features traditionally associated with both database and expert systems software. Database software usually provides data manipulation flexibility and user interface tools, while expert systems tools offer sophisticated data representation and reasoning capabilities. Ultimately, it would be desirable to incorporate tools from both categories; in the early prototypes, this was not necessary or practical. Thus, two separate approaches naturally emerged, each centered around one of these packages. Up to the present, most of the effort has focused on the method utilizing an expert system, and that method has enjoyed somewhat greater success. An earlier approach to the problem made use of SunUNIFY database software. ${ }^{5}$ This effort was abandoned because of the very limited capabilities of the SunUNIFY software.

\subsection{EXPERT SYSTEM METHOD}

An expert system software shell and several $C$ language programs were used to develop an operator procedure prompting aid that runs on a Sun 4/60 (Sparc Station 1) Workstation. This method was preferred by some software development personnel because of the possibility of using its decision-making capability at a later date.

\subsubsection{Computer Hardware and Software}

Development of the expert system for procedure prompting was initially begun on a National Cash Register personal computer (PC), a clone of IBM PC Model AT (microprocessor-based, 80386 chip). This expert system software was later transferred electronically to a Sun 3/60 Workstation that eventually was upgraded to a Sun $4 / 60$ (Sparc Station 1). The Sun Workstation has a large memory capacity, full-color capability, the capability for processing information at high speed and for high-resolution displays, plus the capability to communicate with other systems on the network via Ethernet. The Sun Workstation also allows the programmer to interface programs written in development languages such as Fortran, $\mathrm{C}$, and LISP with the Knowledge Engineering System (KES) expert system software shell. The Sun Workstation uses the UNIX operating system.

Newer versions of the expert system software shell were required for each change in hardware. This was required because each software package is designed for compatibility with a specific computer model and a specific kind and version of the operating system.

An expert system software shell was chosen instead of a computer language such as LISP or Prolog because it simplifies de'elopment of an operational expert system. The logic for solving problems is already' built into the expert system shell. The KES expert system software shell ${ }^{6,7}$ was selected for use in developing this expert system.

In using the KES software shell the knowledge base author may employ three types of reasoning processes to achieve the desired goal, that is, any of the following three inference engines defined by KES may be used in problem solving:

1. The production rules (PS) subsystem uses rule-based deduction to solve problems. The knowledge base contains rules of the form "if $\mathrm{x}$, then $\mathrm{y}$," where $\mathrm{x}$ is the antecedent, 
condition, or premist and $y$ is the consequent, conclusion, or action. In antecedentdriven deduction, the occurrence of antecedents "triggers" the application of an appropriate rule to infer the consequent. In consequent-driven deduction, the system is directed to obtain a snecific goal. In PS subsystems the rules are evaluated via a "depth first" search of the attribute hierarchy, resulting in backward chaining of rules.

2. The hypothesize and test subsystem inference technique utilizes frame-based knowledge representation and employs abductive reasoning (hypothesis formulation and subsequent verification by testing) to solve problenis. Frame-based knowledge representation uses a network of nodes connected by relations and organized into a hierarchy. ${ }^{8}$

3. The statistical reasoning (Bayes' Theorem) subsystem technique combines pre-existing knowledge with data to determine statistical pattern classification based on Bayes' Theorem.

All three inference engines usc a similar, goal-directed approach (backward chaining) in making inferences.

Programs in $C$ language are used to import external information into the KES expert systems shell and to contain appropriate SunView ${ }^{9}$ (a user-interface toolkit) commands, which are called to display information in scrollable windows.

\subsubsection{Description of Expert System Procedure Prompting Method}

This expert system prompts the operator for startup of the EBR-II reactor by leading him through the preparatory, direct, and approach-to-power procedures and providing direct access to relevani information at each step.

Preliminary information is displayed on the workstation screen at the beginning of each set of proc adures. First, the operator is shown the current revision number and approval daies of the startup instructions and checklists used in preparing the prompting procedure (see Fig. 1). Next the operator is given some introductory information relevint to the overall set of procedures. Then the operator is asked to enter the run number for this startup procedure.

This expert system prompts the operator to select a step in the procedure (using the mouse button), carry out the instructions, and complete the checklist (see Fig. 2).

Preparatory, direct, and approach-to-power procedures are broken down into groups with a variable number of steps within each group. In most groups, the last step is a control point. All startup instructions preceding a control point must be completed satisfactorily, and a shift supervisor's approval is required before proceeding past a control nnint. The expert system control logic ensures that the operator completes all instructions within a group and that the status of all checklist items within the group is "ok" before being allowed to proceed past a control point. Control points occur in direct procedures and approach-to-power procedures, but not in preparatory procedures. At the control poiiit, a shift supervisor is required to enter the correct password (see Fig. 3) in order 10 ) continue. The system control logic repeatedly sets the status of the control point step equal to "not ok" if the password is incorrect, and thus prevents advancement to the next group. A warning message is also displayed to inform the operator that advancement to the next group is not allowed until all steps are completed satisfactorily. 


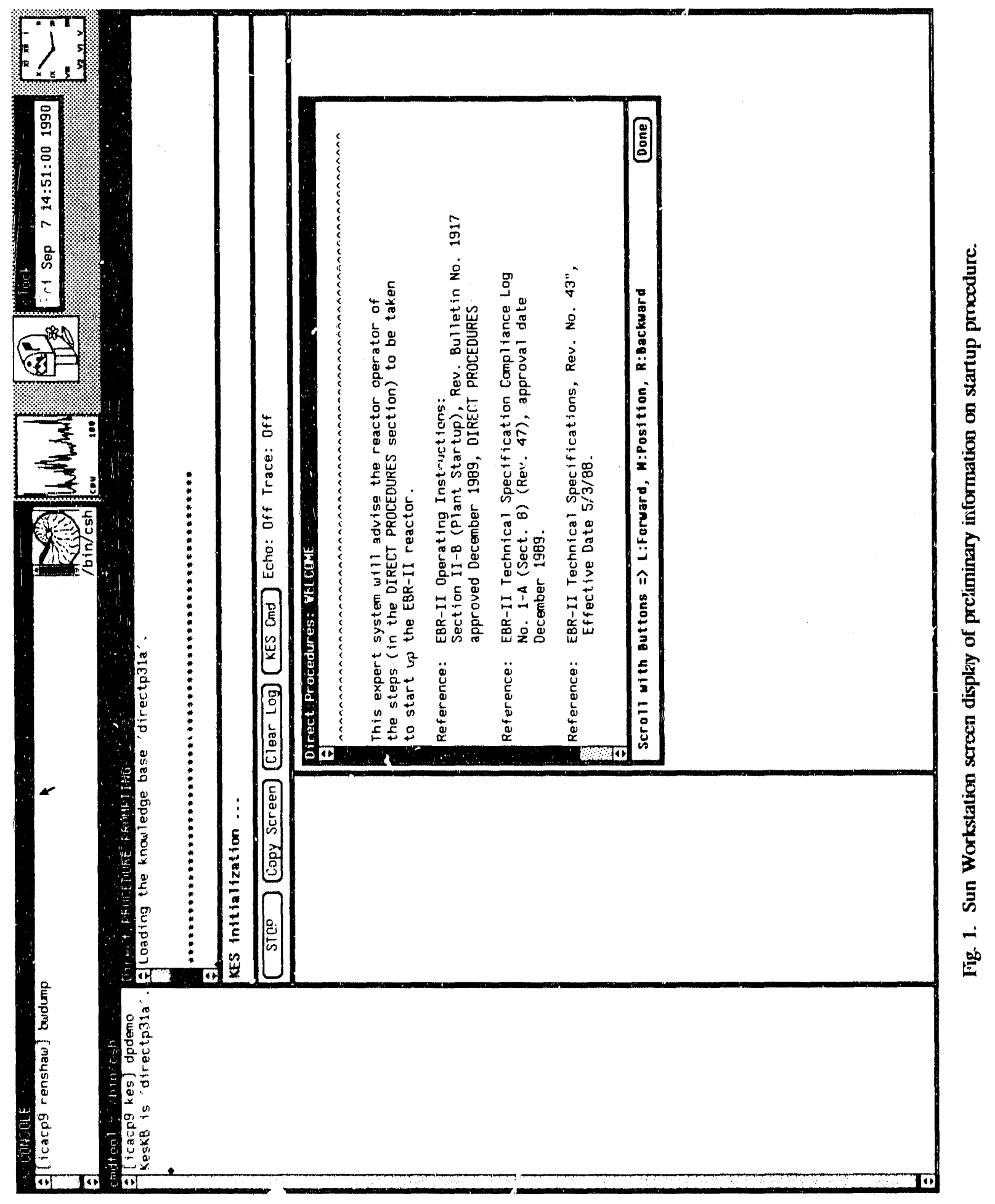




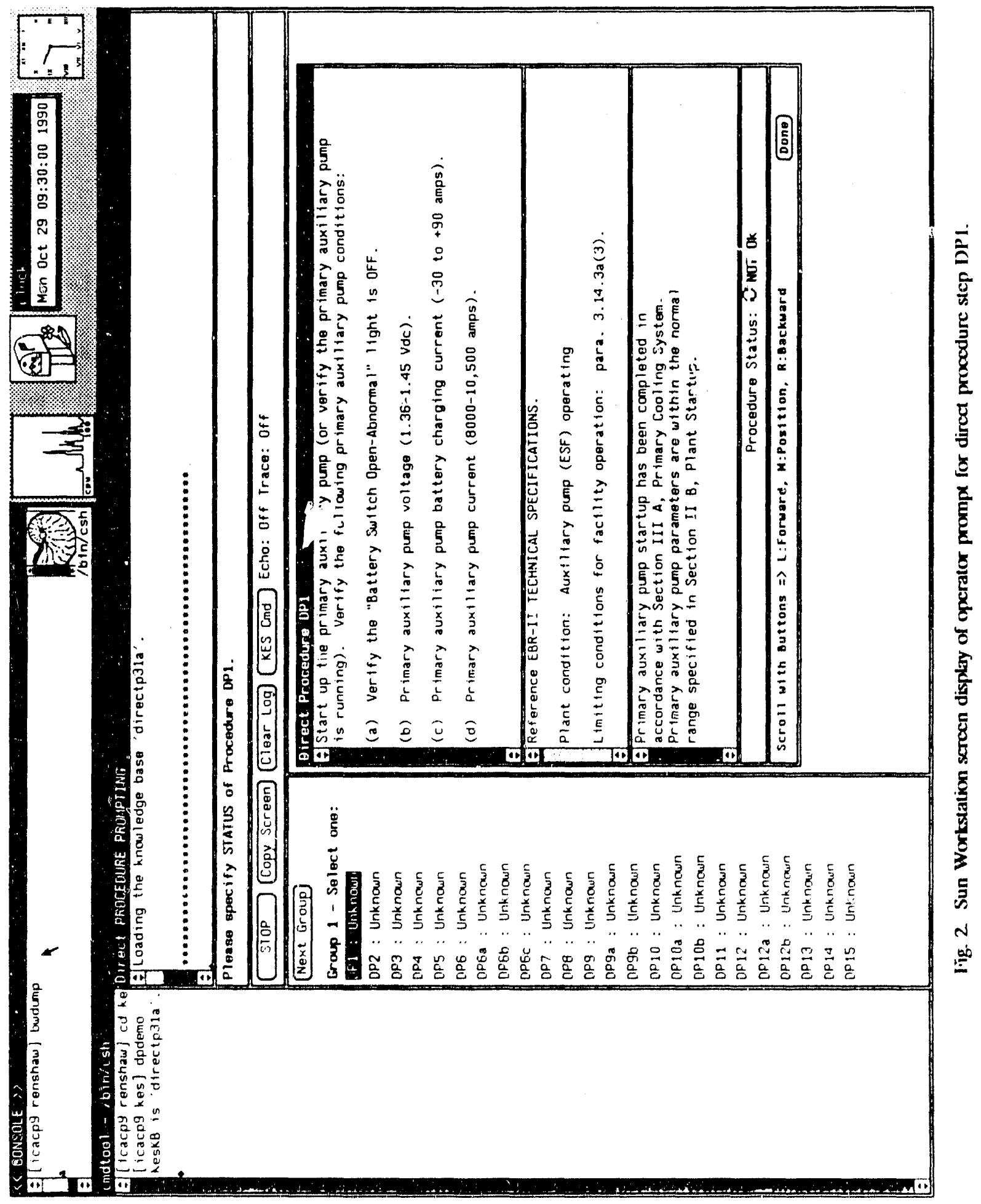




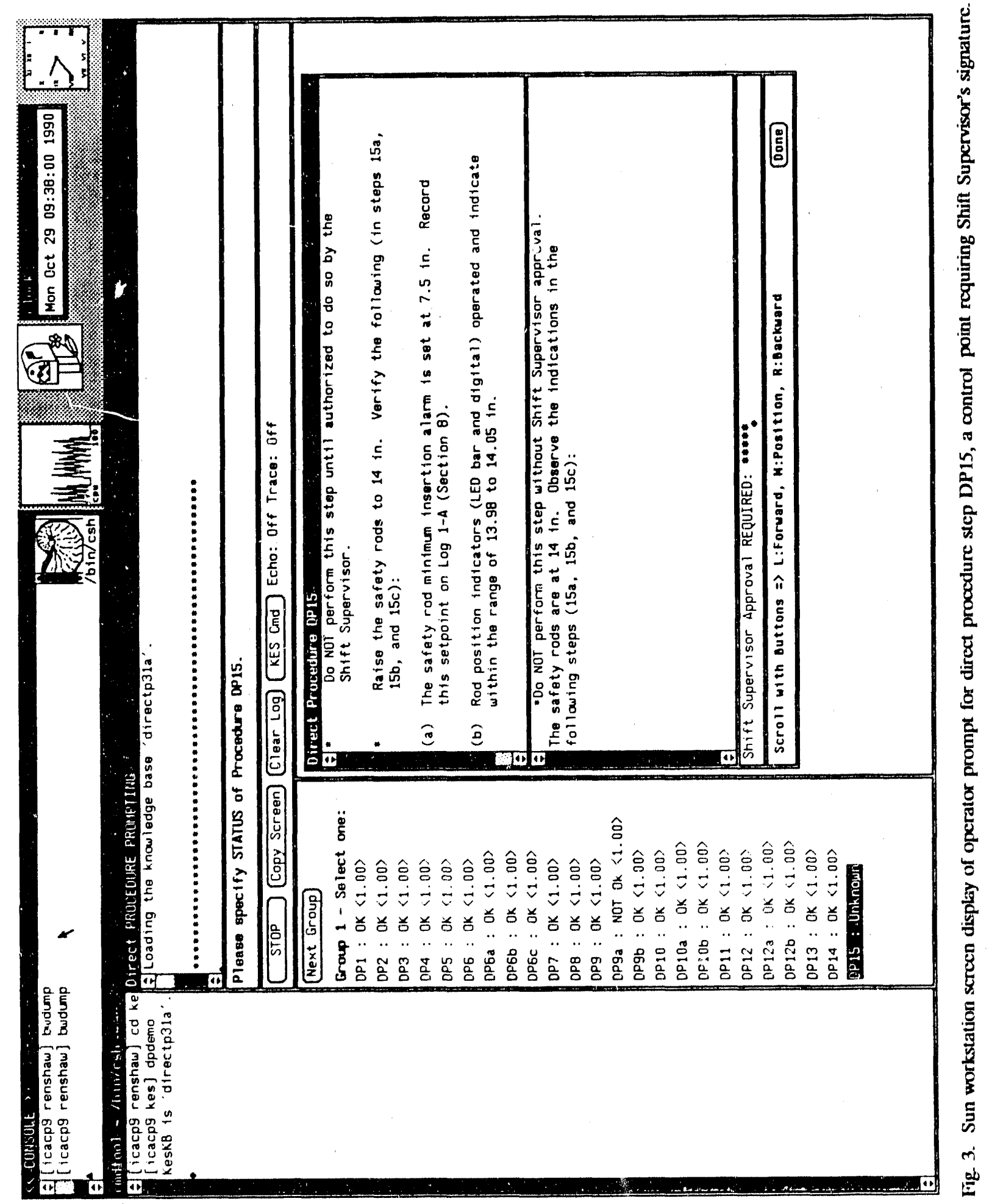


An operator is asked to enter the status for each step in the procedure using the mouse button (see Fig. 4), and it is recorded in the startup data record. There are two response options: "ok" if the tasks described in the instructions for that step have been accomplished and the status condition is satisfactory, and "not ok" if the required condition has not been met or is unsatisfactory. The default is "not ok." In addition, the operator is asked to enter his initials at each step in the procedure (see Fig. 5). The date and time are recorded automatically at the time the operator enters the status for the step. The list of steps in the group and the status of each step within the group can be viewed on the workstation screen while the operator is working in that particular section of the startup procedure (see Figs. 2 through 5). Notice that the step selected by the operator is highlighted.

Windows are used at each step of the startup procedure to display information relevant to that particular step (see Fig. 6). Multiple windows display instructions, checklist, and technical specification references to provide information to assist the operator in checking the status of each step in each section of the startup procedure. Only information relevant to a particular step is shown (in the following order): instructions, technical specification references (if applicable), and checklist.

For some steps in this procedure, data input by the operator is required (see Fig. 6). Operations personnel must take a direct reading from the appropriate instrument in the control room, in the field, or from the DAS, and enter that data into the checklist data field when requested. These data will be deposited in a temporary run-time data file and at the same time appended to the startup data record. This method of data collection allows the operator some control in assessing the integrity of the data.

When each section (preparatory, direct, or approach-to-power) of the startup procedure is completed, the data record will be displayed in a "pop-up" window on the workstation screen (see Fig. 7). The operator can use the mouse to scroll the window on the workstation screen up or down to read the entire text or click in the left column of the window to point to any portion (beginning, middle, end) of the text. The final output from this expert system is a startup data record file in the workstation directory and a printed copy of the data record. The data record duplicates the technical specifications compliance log and is needed as documentation of the startup action. The data record contains the initials of the reactor operator who checked the status of the step, the names of operations personnel who have given approval to advance at specific control points, the time and date (recorded automatically at each step) of these actions, and data relevant to components of the reactor system.

Another of the operator's options for retrieving information is available via the windows on the Sun Workstation. If the operator is running a startup procedure, another window may be opened on the Sun Workstation in order to call up the data record being generated for the procedure that is being run, or for any other data record in the workstation directory.

\subsubsection{Description of KES Expert System Features Used for Procedure Prompting}

$\mathrm{M}: n$ y of the features of the KES expert system software shell were not fully exploited because the limited scope of the problem does not require their use. However, our objective of developing the operator APP aid was achieved by taking advantage of those features that could be applied to our task. 


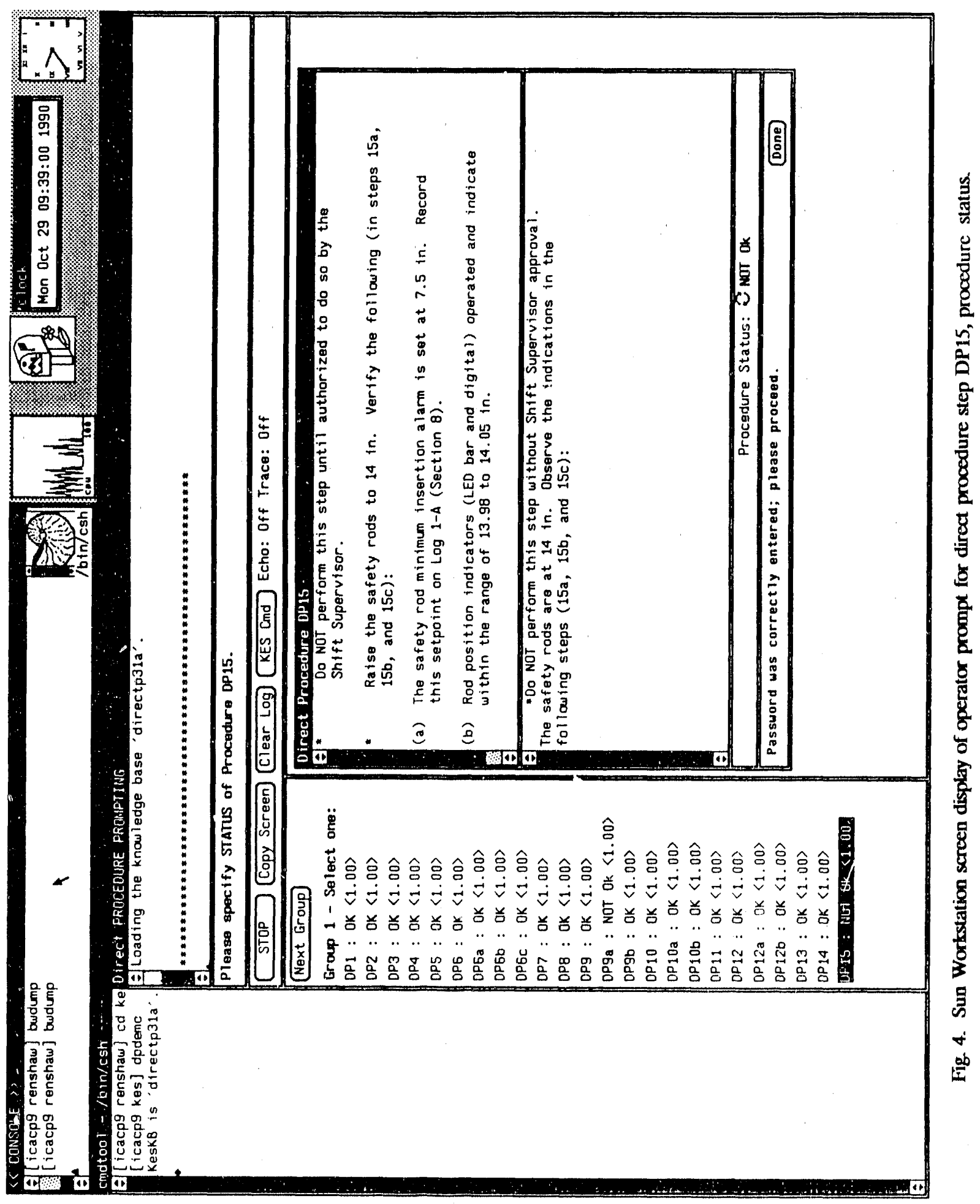




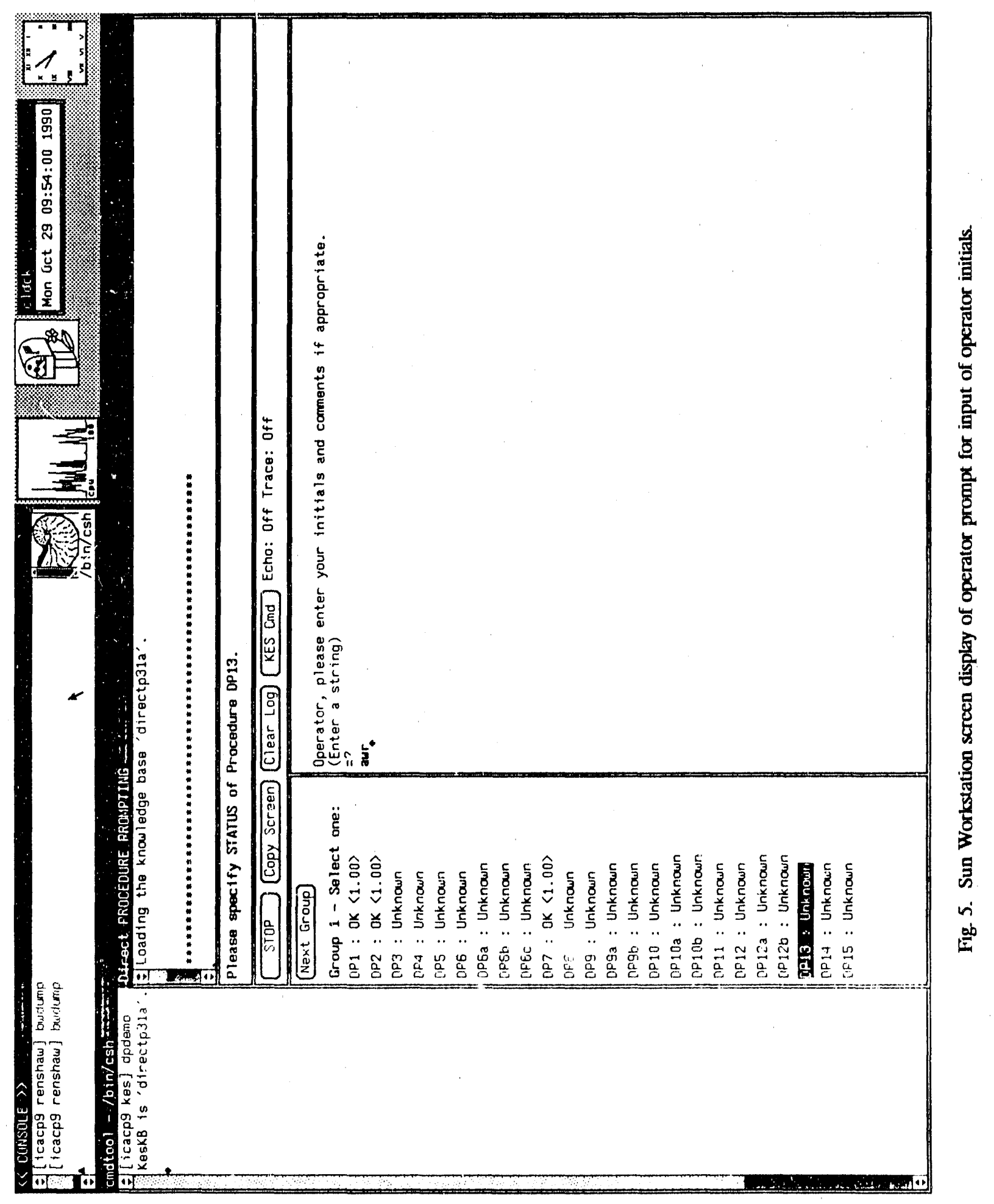




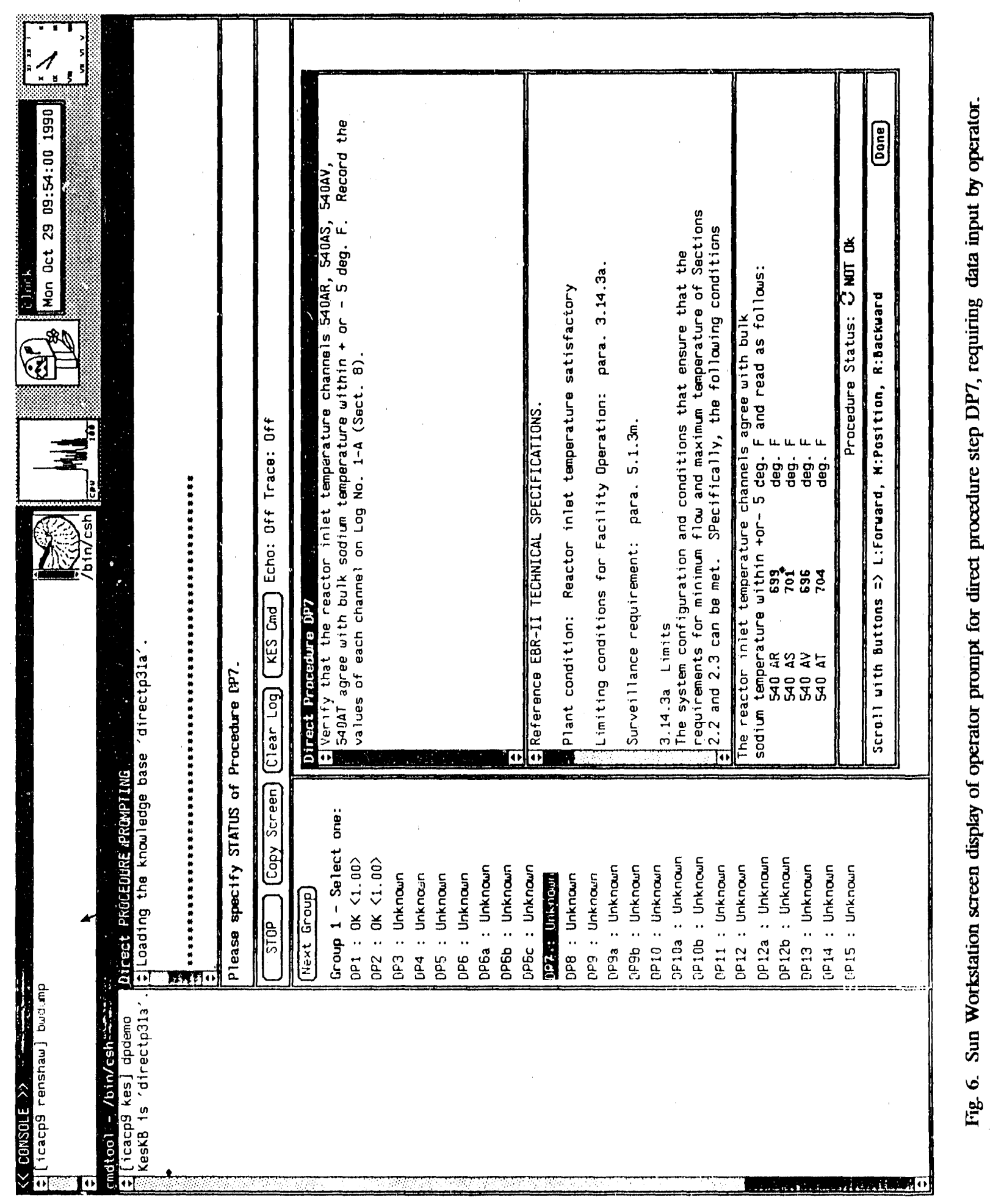




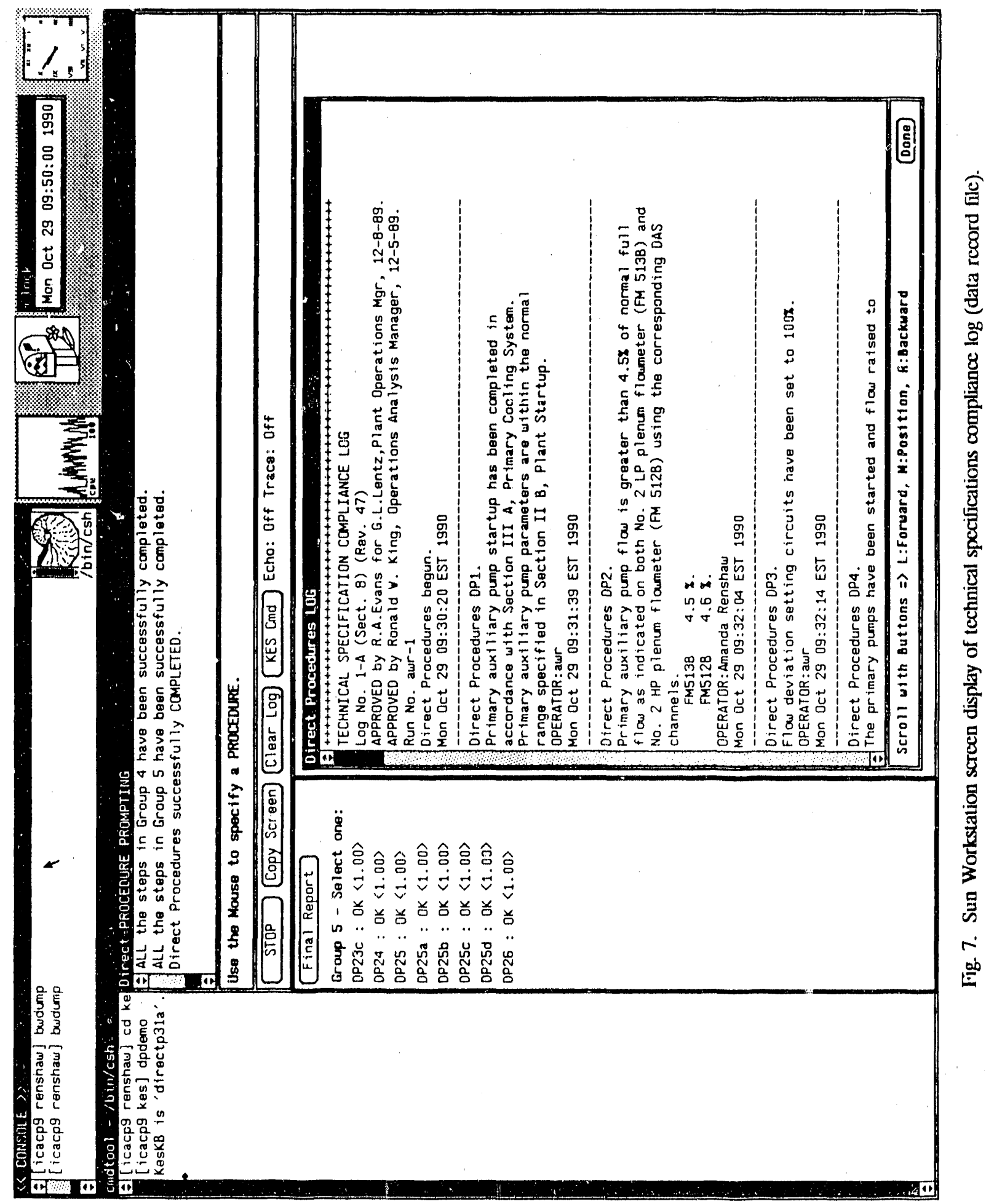


The KES expert system can perform event-driven (forward-chaining) inferencing through the use of demons. A demon is composed of two parts, a guard and a body. The guard contains conditional statements that are evaluated, and the body contains a list of commands that KES performs in order. This expert system operator aid uses a demon to promet the operator to select a step, read and carry out the instructions for a startup that appear in the pop-up window (see Fig. 3), and complete the checklist by entering data (if requested) and determining the status of each step.

The KES expert system class structure was used to define groups of procedures as classes. Preparatory procedures, direct procedures, and approach-to-power procedures were each defined as a class. Then the steps in each procedure were defined as members of the class. Taking advantage of the class structure resulted in a reduced number of instructions in the computer program for stepping through the procedures.

Members of the procedures class are the steps in the procedures and are designated: PP1 through PP12 in preparatory procedures, DP1 through DP26 in direct procedures, AP1 through A.P8 in approach-to-power precedures (including a number of subsidiary steps). Each class definition includes attributes that describe the characteristics of the class.

Attributes defined under the procedures class are

1. Status. This attribute is used to determine whether the status of each step in the procedure is "ok."

2. ShiftSupvSign. This attribute is used to determine whether the Shift Supervisor's approval is required for each particular step.

3. DataInput. This attribute is used to determine whether data input is required for each particular step.

4. TechSpec. This attribute is used to determine whether there is a technical specifications reference applicable to this step.

5. Group. This attribute is used to assign each step in the procedure to a group.

Data are also defined as a class so that data values can be infut by the operator for those particular procedure steps in which data input is required.

The members of the data class are named, when possible, after the instruments that supply the data requested. For example, tc503D is the data class member for a thermocouple reading, and $\mathrm{f} 1512 \mathrm{~B}$ is the data class member for a flow indicator reading.

Attributes defined under data class are

1. $p p, d p$, and ap. These mnemonics are used to identify the procedure that the data are associated with; that is, preparatory procedures, direct procedures, or approach-topower procedures.

2. Dvalue. This is the attribute for temporary storage of the data value that the operator is requested to input to the checklist.

3. before text. This attribute is delined to hold the text that precedes the actual data value on a line of text in the record file. 
4. after_text. This attribute is defined to hold the text that follows the data value on a line of text in the record file.

The attributes listed above are defined in the elass section of the expert system to describe class members specifically. If an attribute is used globally, then the attribute is defined in the main attributes section and not in the class section of the expert system program.

All status attributes are assigned a default value of "no." This reduces the number of assignment statements in the input data file to only those steps requiring "yes."

Members of both the procedures and data classes are defined in an external data file. This data file is called by the actions section of the KES expert system program $(0)$ read the class member names and attribute values.

Externals are commands used by the KES expert system software to retricve information outside the expert system shell. This expert system uses externals to get the data file, to get date and time, and to interface with $C$ programs outside the expert system shell. Several $\mathrm{C}$ programs are used with the operator prompting expert system to generate scrollable windows to display information to the operator. Logic in the expert system determines which information is displayed in the windows for each step.

\subsection{DATABASE SOFTWARE METHOD}

\subsubsection{Introduction}

The use of a database management system (DBMS) shell for the automated procedure prompting software has several very attractive features: (1) a high-level procedural language (such as dBase IV) greatly simplifies programming of menu-driven task sequences; (2) the data generated in each startup run are readily accessible for report generation; (3) automatic checking and verification of data entrics is facilitated; (4) tic-in with DAS-generated data can be accommodated; and (5) pop-up windows are available for on-demand help or "more details" messages.

On the other hand, during development of the PC-based dBase IV prototype, an unexpected limitation was encountered: the apparent inability of the dBase IV program to "call" external graphics programs. One important requirement of the prompting program is to allow the operator to select time-history graphics of important plant parameters and calculations in order to help assess the plant status and thus determine whether proceeding to the next step is warranted. After work on the PC-based DBMS program was suspended, however, dBase IV-compatible third-party graphics software was discovered that would readily satisfy the graphics needs for startup procedure prompting.

Procedure prompting requirements may be said to fall into either the "pick" or the "roll" category. With "pick," the procedures are grouped into batches, within which the sequencing of each task's execution and checkoff is left to the discretion of the operator. On the other hand, the "roll" category covers the case in which individual procedures must be accomplished in the specified sequence. The database prototype includes both categories. 


\subsubsection{Description of Database Prototype Procedure Prompting Method}

The database prototype for the EBR-II startup was written in the dBase IV language (Version 1.0) as a menu-driven system. The main menu (see Fig. 8) gives the operator a choice of sclecting which of the three main sections of the startup proceclures is desired. (Currently, only the preparatory procedures and the first part of the direct procedures are implemented.)

Upon selecting the preparatory procedures (choice 1), the operator is presented with the run numbers (and dates) of those runs already in the database (see Fig. 9). The preparatory procedures for these runs may or may not be completed, that is, and operator has the option of restarting the program or run that may have begun on a previous shift. He may select a completed run to display a summary report. Figure 9 shows that the operator has selected run 1339. The following screen (see Fig. 10) shows a summary report of the current status. of the preparatory procedures "checklist," including which steps have yet to be completed ("none"), whether or not the run followed a normal shutdown ("yes"), the status of the main parameter of interest (the bulk sodium temperature), and a list of the operators who participated in the startup. The database record of the checklist disposition includes the time and date of each entry (recorded automatically) and the initials or name of the operator.

At this point, the operator chooses (Fig. 11) what action is to be taken with the preparatory procedures, that is, either to revisit the prompting screen to finish or alter cliecklist entries, or to proceed to the next set of procedures (the direct procedures), which is allowed only if the preparatory procedures are completed satisfactorily. Upon choosing to revisit $(R)$ preparatory procedures, the drift in the bulk sodium temperature since its initial recording is noted, and then the "pick" style screen for the preparatory procedures is displayed (Fig. 12). All 12 steps of these procedures are displayed, and as they are executed the operator's initials are entered in the box beside a summary statement of the procedure. The initials are validated against a master list of eligible operators.

If the summary checklist item description shown is too brief and more clarification is required, the operator can locate the cursor in the space adjacent to the appropriate step and select the $F 1$ function key on the $P C$ to call up additional information. The window at the bottom of Fig. 12 was called up as an example of a further explanation, in this calse, of task 4 (Work Requests Review). Another feature (not yet implemented) would be to call up summaries of the technical specifications for those tasks denoted by "*" as technical specifications surveillance items. Also, it was originally intended to have appropriate graphical displays available for callup via function keys in order to present additional pertinent information; however, such graphics calls were not available at the time of development. 


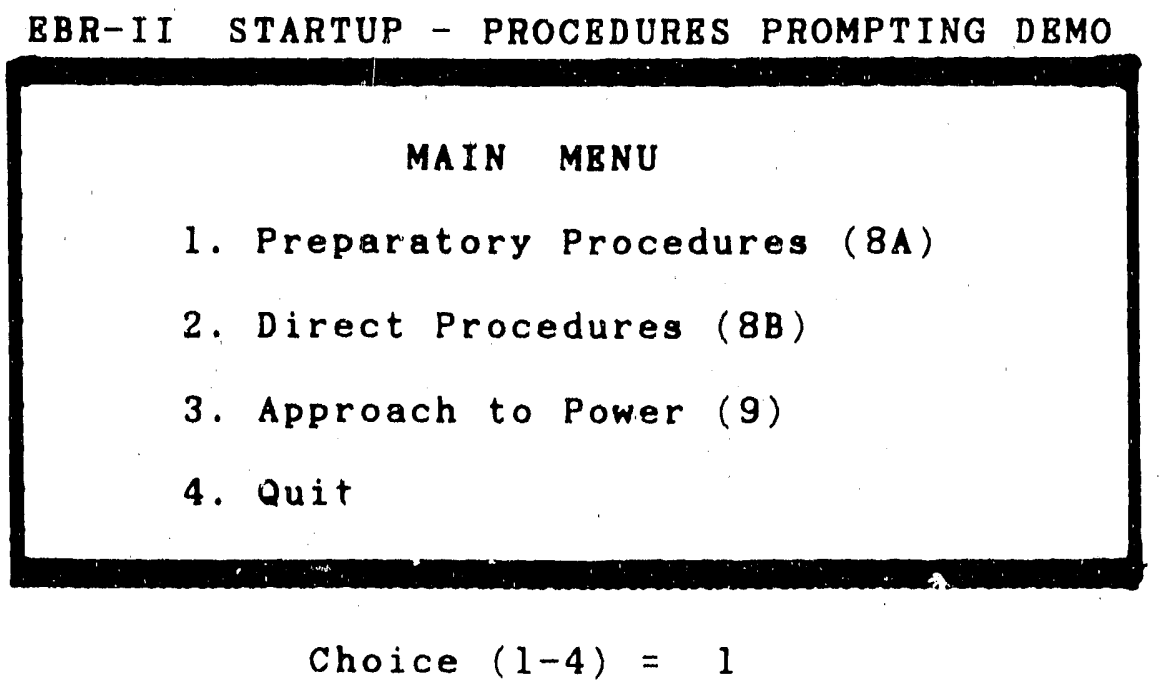

Fig. 8. Database prototype, main menu.

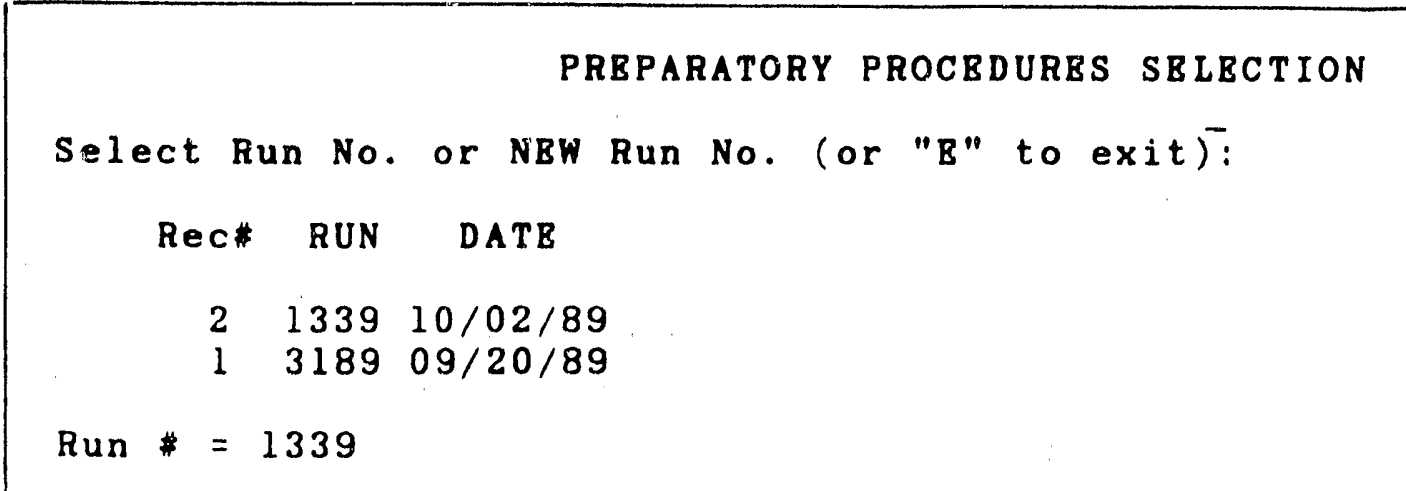

Fig. 9. Database prototype, preparatory procedures run selection screen. 


\section{Preparatory Procedures - Run \#1339 Form Rev. \# 335 \\ Run began at $08: 32: 54 \mathrm{hr}, 10 / 02 / 89$}

The following steps are not yet done: None.

The run followed a NORMAI shutdown.

Bulk sodium temperature was $702.39 \mathrm{~F}$ at $14: 05: 10 \mathrm{hr}, 12 / 20 / 89$

The participating operators for run 1339 were:

Syd Ball

Amanda Renshaw

Jim White

Dwayne Fry

Fig. 10. Database prototype, cxample summary status report for preparatory procedures section of startup.

PREPARATORY PROCEDURES ACTION MENU

$R=$ Revisit PP prompts to complete/alter run

$D=$ Proceed to Direct Procedures Prompter

$E=E \times i t$

Choice $(R, D, E)=R$

Note: Current Bulk sodium temp $=699.76 \mathrm{~F}$

Drift has been $-2.63 F$ since 14:05:10 12/20/89

Iig. 11. Databasc prototype, preparatory procedures action menu. 


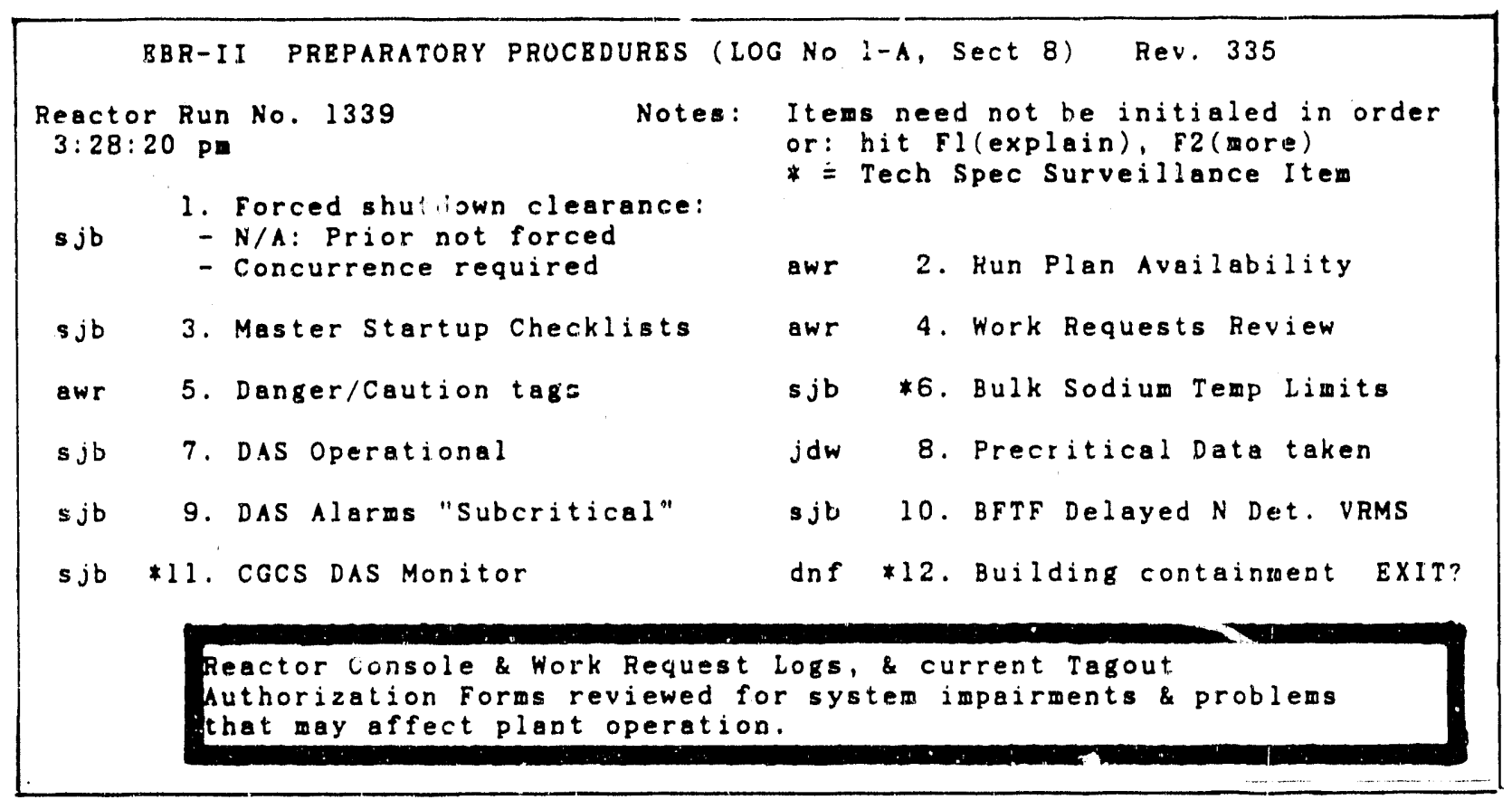

Fig 12. Database prototype, "pick" style checklist screen for preparatory procedures.

Upon selecting the direct procedures option (2) from the main menu, the operator is allowed the choice of existin "runs in the database to expand upon. Data for the first part of this procedure are obtianed from a $C$ program that randomly generates DAS data. The DAS readings, along with permissible ranges, are displayed, and based on this information the program infers the state of the primary auxiliary pump (see Fig. 13, "Primary Auxiliary Pump IS Operating" in this case). The next display is the "pick" style checklist screen for direct procedures (see Fig. 14). Notice that data collected both manually and from the DAS are displayed on the screen. The window at the bottom of the screen provides a more detailed explanation of task 2 and is accessed by the operator through use of the F1 function key. The balance of the direct procedures are not yet implemented in this prototype. 


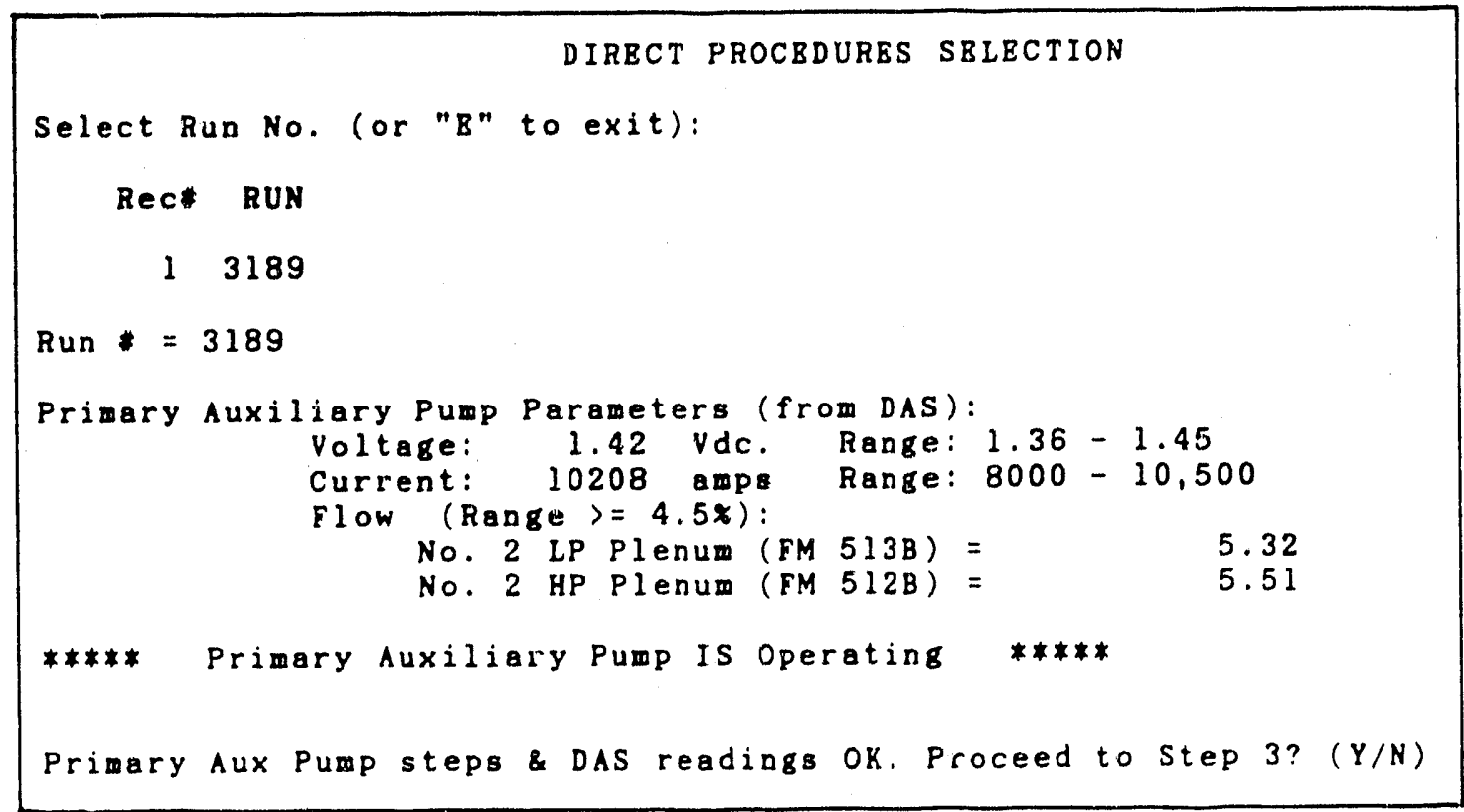

Fig. 13. Database prototype, direct procedures run sclecuion with summary status report.

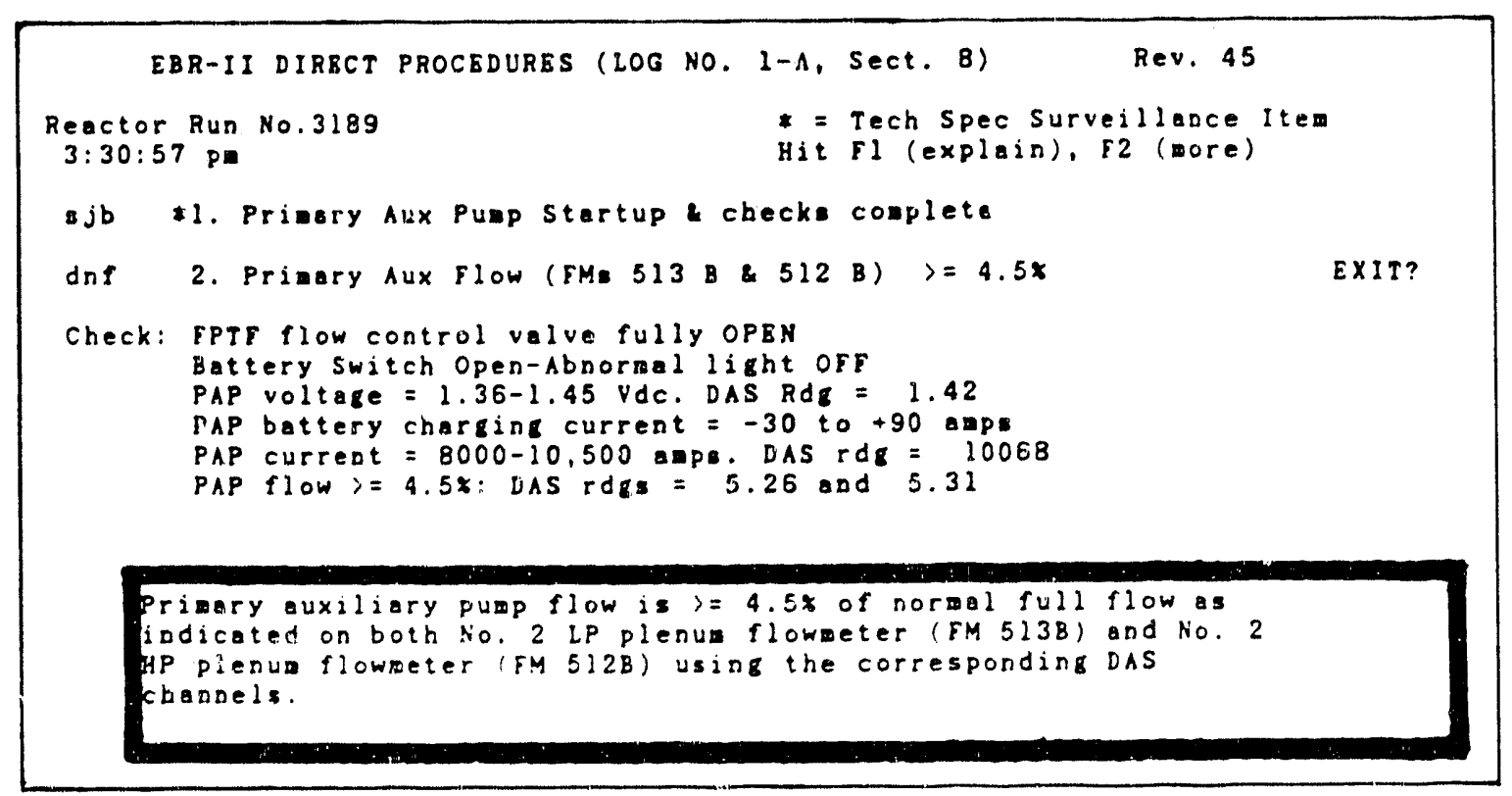

Fig. 14. Database prototype, "pick" style checklist for first part of direct procedures. 


\section{RESULTS}

The expert system prosedure prompting aid, when installed on a Sun Workstation at EBR-II, can guide the operator through the preparatory procedures, direct procedures, and approach-to-power procedures for startup of the EBR-II reactor. Supplemental information for each step is presented to the operator in a window scheme designed to) make the information more easily accessible and thus assist the operator in performing each task in a more timely manner. It also improves the safety aspect of the startup operation by reducing stress on the operator and thereby increases alertness potential. When startup has been accomplished, a data file record (technical specifications compliance log checklist) will have been generated and stored in a file on the workstation and can be queued to the printer.

The operator prompting expert system has been demonstrated to DOE (December 1989) and ANL-W (June 1990) personnel during visits to ORNL. Also, presentations

with viewgraphs describing the expert system have been shown to operations, engineering, and maintenance personnel at ANL-W (March 1990). The completed expert system for automated startup will be demonstrated at ANL-W during 1990.

A critical review of this expert system operator aid for procedure prompting will be made by staff personnel at ANL-W and reported to ORNL. A separate critical analysis will be made by human factors personnel at ORNL. After reviewing the results of these reports, careful consideraition will be given to making whatever changes may be required to improve this prompting procedure.

The database version of the startup procedure prompting demonstration was also reviewed by EBR-II staff members, human-machine interface (HMI) consultants, and other interested parties. At the time of the revie'ss, the apparent limitation of Dbase-IV to accommodate graphics (subsequently overcome) led to the suspension of work on this approach. Other alternatives to the current database system are being pursued at a lower level, including investigations of similar AECL work on the CANDU-3 procedureprompting system using MacIntosh Hypercard type software. 


\section{CONCLUSIONS}

A demonstration of the expert system method for automated procedure prompting (APP), when installed at the EBR-II site at Idaho Falls, will verify that this computer aid can assist reactor operating personnel in several ways. APP can improve the operator's performance in starting up the reactor by providing supplemental information (such as technical specifications references, instructions, and technical specifications compliance logs) in pop-up windows, thereby reducing the time involved in searching for information through voluminous texts and records. APP can improve the accuracy of record keeping by automatically recording date, time, and other appropriate information at each step of the procedure. APP can improve the safety of the startup operation by reducing the time involved in carrying out the startup tasks the operator is required to perform and thereby reducing operator stress and increasing alertness potential. A human factors review of this APP method has resulted in improvements in the kind, amount, and arrangement of information presented to the operator. A human factors assessment of this APP will aid in determining whether workload and stress on the operator in reactor operating performance are improved.

The database method for procedure prompting has the potential for useful and efficient automated procedure prompting and should be pursued, although work on the prototype is being deferred at present. 


\section{RECOMMENDATIONS FOR FUTURE WORK}

Additional improvements to the expert system procedure prompting operator aid that could further increase its usefulness to reactor operators are described below. The prototype system described in this report utilized relatively simple logic to control the process of presenting the procedures to the operator; later versions could easily incorporate sophisticated rules as part of the expert system, enabling the computer to manage intelligently the interactions among the operator, the procedures, and the DAS. Operator aids can increase the efficiency of operating nuclear power plants and, in turn, reduce the cost of operation. Therefore, more nuclear power plant applications ${ }^{10.12}$ should be considered, several of which are described below. Computer security is an important consideration when using an expert system in the operation, control, or maintenance of documentation records of a reactor system. Any computer used for these functions associated with a reactor system should include a modern state-of-the-art personnel identification system such as a biometric device to guard against access by unauthorized personnel and to ensure positive identification of each individual user. In addition, certain applications software and archived records should use advanced security technology to protect against alteration or destruction of the recorded data. Because this procedure prompting operator aid for startup is being developed in anticipation of its application to the ALMR, increased computer security should be considered and tested on the EBR-II reactor.

\subsection{IMPROVEMENTS TO PROCEDURE PROMPTING}

During visits with EBR-II and GE Nuclear Energy personnel several suggestions were made for increasing the value of the procedure prompting aid to the operators. Some are described in the foilowing paragraphs.

A future version of this expert system should obtain data directly from the DAS for instruments interfaced with the DAS. The expert system features can be used to validate the data, inform the operator of the status, record the data, and proceed to the next step if the status is satisfactory.

A new database should be selected and installed on the Sun Workstation. The new database should be large enough to hold data values from startup runs, maintenance records, technical specifications, emergency operating procedures, and other sources. In other words, the database should be large enough to hold all records that need to be accessed quickly by the reactor operator during the performance of his duties.

This database should aceept for permanent storage data values collected during the startup run by the KES expert system. These data values can then be retrieved if necessary to review actions taken during startup. These data files should be writeprotected to prevent alteration.

The EBR-II control room has a monitor that displays plots of plant parameters vs time for all instrumentation currently interlaced via multiplexers with the DAS. A means of plotting reactor data that is calculated during startup is needed by control room operators. This is presently a time-consuming task that slows down the startup process. It is iecommended that a graphics software package be installed on the Sun Workstation containing the expert system APP. This soltware could be called up in a separate window 
to generate plots, as needed, for calculations performed during the startup operation by the expert system.

\subsection{OTHER OPERATOR AIDS}

\subsubsection{Equipment Maintenance Record Database ${ }^{13}$}

Equipment maintenance records should be recorded in a database so that they can be accessed for trending studies, scheduling of maintenance and calibration services, and monitoring compliance with technical specifications surveillance requirements.

\subsubsection{Technical Specifications Monitor ${ }^{14,15}$}

Technical specifications should be deposited into a database so that they can be accessed by menu to obtain pertinent information when needed by the operator. These specifications lend themselves to access in a variety of ways (by paragraph number, by equipment name, by plant condition, by keyword, etc.) to facilitate their retrieval by the most efficient method.

\subsubsection{Emergency Operating Procedures Advisor ${ }^{16-20}$}

An Emergency Operating Procedures (EOPs) advisor should be developed as an operator aid. It should be an advisor to the operator, not an order to take action without further assessment of the situation by operations personnel. In this case, a symptom-based system might best serve the reactor operator. Rules in the expert system could be used to decide whether an emergency condition exists. Then the operator would be notified of the specific emergency condition, the recommended action to be taken (as specified in the EOPs) to remedy the condition, and the reasons for the action. Rules can be invoked by the KES expert system, and resulting conclusions can be displayed on a monitor to advise the operator of recommended actions to be taken.

\subsubsection{Portable Computer}

Use of a small portable "roving" computer with a DBMS-based prompting program is also being considered for use in accomplishing field procedures (away from the control room). For this case, data from the portable computer would be downloaded to the main computer following each tour of duty. Use of bar codes on the field equipment would facilitate data acquisition and validation.

\subsection{COMPUTER SECURITY}

The nuclear industry should move in the direction of improved computer security to protect software and data records from access by unauthorized users. ${ }^{21}$

Current technology is providing innovative personnel identification systems to protect against unauthorized access to computer systems via attempts to more accurately identify the potential user. A computer system can verify the identity of those attempting 
to gain access to it by the use of passwords and IDs, smart cards or tokens, or biometric devices.

Biometric devices use unique physical characteristics of the individual such as voice, fingerprint, hand geometry, and eye retinal patterns for positive personnel identification.? A system that compares signatures is also a biometric device. A biometric system scans or replicates the characteristics to be measured and compares the information to stored data.

The International Biometrics Association, formed in 1986 and located in Washington, D.C., is developing standards in such areas as error-rate measurements and system interfaces. ${ }^{23}$ The yardstick by which all biometric systems are measured is the error rate. False negatives (type I error) are those errors that prevent authorized users from gaining aceess because of an inaccurate reading of the biometric parameter. False positives (type II error) are those errors that occur when an imposter gains access.

Voice-recognition systems can be used as a security device to identify the individua! speaking, but (as is true of other personal identification systems) they are not $100 \%$ foolproof. Voice prints of authorized users are recorded and stored in the computer, later to be compared with the voice of the person trying to gain entry. Acceptance levels, based on probability that the voice is, in fact, that of the person who is authorized, are required to be set. If the person has a cold, is hoarse, or there is a change in tone or inflection of the voice, the computer may not consider the voice input as a good enough match with the voice record, and thereby refuse access.

A fingerprint personnel identification system can also be used for authenticating access to data. This system consists of a small scanning device connected to the user's workstation and software installed in the host computer. The system scans a person's fingerprint, digitizes and encrypts it, stores it in a database, and later matches the fingerprint it is reading with the one stored in the database to verify identification. ${ }^{24}$ With fingerprint identification systems the lowest type I error rate (false negatives) yet achieved is 1 in 1,000 , while type II errors (false positives) have been reported as low as one in one million. ${ }^{23}$

A retinal scanning system is the latest state-of-the-art technology for personnel security identification. This device records the unique retinal blood vessel pattern at the back of the individual's eye. The error rate for false positives and false negatives in retinal scans are both less than one in one million, which is considerably lower than the error rate of one in one thousand false negatives for document fingerprint systems. An argument against this device is that some potential users are reluctant to submit to a light scanning device focused into their eyes because of fear of laser beams. In fact, the scanner light source is a harmless infra-red light-emitting diode of ultra-low intensity. The retinal scanning system measures the reflected light to determine the pattern of the retinal vasculature.

Public-key technology secures data files. A digital signature can be employed to protect a file record against unauthorized changes. Two soltware security products are used for ensuring the integrity of applications software and data files. One signs a computer file with a i28-bit document fingerprint (private encryption key) uniquely a nerated for the file. The other decrypts (using public-key) the document fingerprint to authenticate files and certify them against unauthorized changes or damage from viruses, system crashes or other causes. Both keys are needed for encryption-decryption. ${ }^{25}$ 


\section{REFERENCES}

1. EBR-II Operating Instructions Sect. II-B, Rev. Bull. No. 1917, November 13, 1989, "Plant Startup" (operating instructions).

2. EBR-II Technical Specification Compliance Log No. 1-A, Sect. 8, Rev. 47, "Functionial Startup Checksheet" (Preparatory Procedures and Direct Procedures), approved December 8, 1989.

3. EBR-II Technical Specification Compliance Log No. 1-A, Sect. 9, Rev. 46, "Approachto-Power Checksheet," approved December 8, 1989.

4. EBR-II Technical Specifications, Rev. 43, May 3, 1988.

5. R. Paviotti Corcuera, C. E. Ford, S. J. Ball, and R. B. Perez, Designing an AI-Environment Prototype for the Automatic Startup of EBR-II, ORNL/TM-11296, Oak Ridge National Laboratory, June 1990.

6. Knowledge Engineering System (KES) Knowledge Base Author's Manual, Production Subsystem (PS), Software Architecture \& Engineering, Inc., Arlington, Va, 1988.

7. Knowledge Engineering System (KES) Knowledge Base Author's Reference Manual, Software Architecture \& Engineering, Inc., 1988.

8. D. Waterman, A Guide to Expert Systems, Addison-Wesley Publishing Co., Reading, Mass., January 1986.

9. SunView Programmer's Guide, Sun Microsystems, Inc., Mountain View, Calif., 1990.

10. R. E. Uhrig, "Use of Artificial Intelligence in Nuclear Power Plants," pp. 210-216 in Advances in Human Factors Research on Man/Computer Interactions: Nuclear and Beyond, proceedings of ANS Topical Meeting held at Nashville, Tennessee, June 10-14, 1990.

11. R. E. Uhrig, "Application of Artificial Intelligence in the U. S. Nuclear Industry," pp. 11-19 in Artificial Intelligence and Other Innovative Computer Applications in the Nuclear Industry, proceedings of ANS Topical Meeting, Snowbird, Utah, August 31 September 2, 1987, eds. M. C. Majumdar, D. Majumdar, and J. I. Sackett, Plenum Press, New York, 1988.

12. R. E. Uhrig, "Applications of Artificial Intelligence in Nuclear Power Plants," Power Magazine, McGraw-Hill, June 1988.

13. T. Kiguchi et al., "Application of Knowledge Information Technology to Nuclear Power Plants," J. Nucl. Sci. Tech. 26, 52-59 (January 1989). 
14. S. A. Laur, "Technical Specifications Advisor Pilot Project for Brunswick Steam Electric Plant--Unit 3," Proceedings of EPRI Conference, Orlando, Florida, June 5-8, 1989.

15. S. A. Laur, "Technical Specifications Monitoring and Maintenance Management," Proceedings of EPRI Conference, Orlando, Florida, June 5-8, 1989.

16. W. Petrick, K. Ng, C. Stuart, and D. Cain, "A Production System for Computerized Emergency Procedures Tracking," Proceedings: 1987 Conference on Expert-System Applications in Power Plants, Boston, Mass., May 27-29, 1987, EPRI CS-6080 [microfiche], pp. 5-61 through 5-68, Expert-EASE Systems, Inc., Belmont, Calil., December 1988.

17. W. Petrick and K. B. Ng, Emergency Operator Procedures Tracking System, EPRI NP-5250M, Nuclear Software Services Inc., Los Gatos, Calif., june 1987.

18. W. Petrick et. al., "Emergency Procedures Tracking System for Nuclear Power Plants," pp. 689-696, in Artificial Intelligence and Other Innovative Computer Applications in the Nuclear Industry, proceedings of ANS Topical Meeting, Snowbird, Utah, August 31 September 2, 1987, eds. M. C. Majumdar, D. Majumdar, and J. I. Sackett, Plenum Press, New York, 1988.

19. J. F. Cheng et al., "Evaluation of an Emergency Operating Procedure Tracking Expert System by Control Room Operators," Proceedings of EPRI Conference, Orlando, Florida, June 5-8, 1989.

20. W. C. Chang and J. F. Cheng, "The Utility Experience of Implementing the Emergency Operating Procedure Tracking Sysiem," Proceedings of EPRI Conference. Orlando, Florida, June 5-8, 1989.

21. S. Sherizen, "Security Nightmares and Necessities in the '90), ISPNews 1(1), 37 (March/April 1990).

22. S. Bakst, "Biometrics: The Future In Security Methods?," Office (USA), 108(1), 19-20) (July 1988).

23. S. Diamond, "Biometric Security: What You Are, Not What You Know," High Technology, 7(2), 54-55 (February 1987).

24. "Fingerprint Device to Scan Visitors to Federal Prison," Wall Street Journal, June 7. 1989, B5 (col. 2), North White Plains, N.Y.

25. G. H. Anthes, "RSA protects files with public-key technology," Federal Computer Week 3(23), 33 (June 5, 1989). 

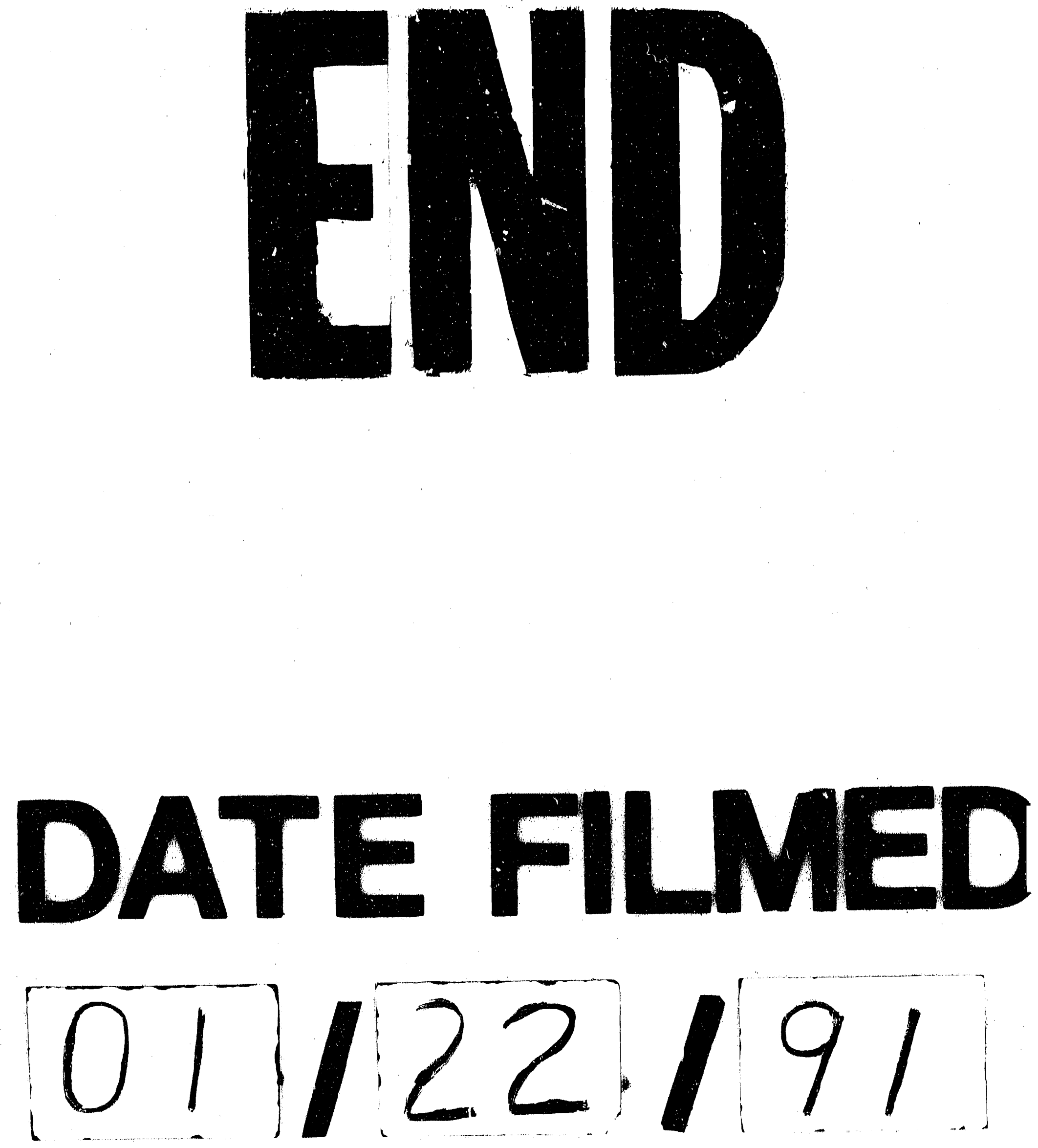
